\title{
ENGAGING THE STUDENT VOICES TO IMPROVE REFERENCING SKILLS AND PRACTICES IN HIGHER EDUCATION: A SOUTH AFRICAN CASE STUDY
}

\section{Singh}

STADIO

Cape Town, South Africa

e-mail: divyas@stadio.co.za / https://orcid.org/0000-0003-4172-6273

\section{Steenkamp*}

e-mail: maryne@lisof.co.za

\section{T. Harmse*}

e-mail: talita@lisof.co.za

\section{J. C. Botha}

Director in the Office of the Vice Chancellor

University of South Africa

Pretoria, South Africa

e-mail: bothajc@unisa.ac.za

*LISOF

Johannesburg, South Africa

\section{ABSTRACT}

Acknowledging that plagiarism includes many different behaviours, this study focusses on one specific plagiarism challenge, namely, acts of incorrect referencing and citation (sometimes called technical plagiarism). Notwithstanding anti-plagiarism policies being in place with penalties for a breach of the rules, Referencing Guides shared with students, additional workshops and tutorial sessions to facilitate the students' understanding of the Institution's referencing rules and standards, higher education institutions continue to experience an ongoing increase in the number of (technical) plagiarism cases, including repeat offenders. While the importance of proper referencing skills and techniques is fundamental to sound scholarship, a further concern is the impact of the accruing penalties on student success, retention, and graduateness. This study actively engaged the students, requiring them to reflect on their prior experiences with various sources of information, as well as their understanding and appreciation of how, why, what, and when to reference the resources used in their studies. The study discovered that students often describe the Institution's approach to teaching the skills of referencing as "alienating" and "punitive" and antithetical to learning. Based on the research data, and comparing the outcomes from other similar research studies, the article propose leading practices that will support higher 
education institutions better prepare students, especially students of the Alpha Generation, for improved understanding and application of institutional norms for academic referencing and citation practices.

Keywords: plagiarism, referencing, citation, ethics and graduateness, academic integrity

\section{INTRODUCTION}

A critical ambition of higher education in the $21^{\text {st }}$ Century is the promotion of qualification relevance and graduate employability. This drive finds equal resonance with technologyintegration, including the use of Artificial Intelligence (AI) as typified by the Fourth Industrial Revolution (4IR). However, in the context of higher education and for the purposes of this article, AI is also a fitting acronym for Authenticity and Integrity. Authenticity in higher education rests on various philosophical assumptions about the nature of truth, reality, ethics, and ultimately, the aims of education (Bialystok 2017) while integrity includes the values of honesty, responsibility and openness to scholarly activity that is fundamental to the legitimacy and value of the education and qualifications which the students earn. In the milieu of the growing global scourge of academic misconduct, assessment fraud, cheating and plagiarism, all of which pose significant risks to the continued credibility and sustainability of the institution of higher learning, authenticity and integrity are critical pillars of higher education. These pedagogical foundations set the parameters for the ethical standards that must inform the architecture of our future technology-driven societies.

It was therefore a concern when our Institution, a registered private higher education Institution in Gauteng (South Africa) noted an increasing spike in the numbers of academic misconduct cases linked to plagiarism, and more particularly plagiarism arising from incorrect citation and referencing irregularities. Like most, if not all, higher education institutions, we have in place anti-plagiarism policies, student support tutorials, and various plagiarism detecting software solutions to support and actively discourage the bane of plagiarism. However, notwithstanding these interventions, the question remained: Why did all these initiatives not alleviate the problem?

A study of the literature reveals that plagiarism includes several different behaviours. Yamada $(2003,255)$ describes plagiarism as the unacknowledged exploitation of another's words, ideas, or both. A further aspect is the acknowledgement that plagiarism may be intentional or unintentional. In the former case, the wrongdoer deliberately sets out to pass off someone else's words, ideas, or artefact as his/her own, while in the latter, the root cause of the problem is often a result of ignorance, misunderstanding and/or inexperience. Both types of behaviour are often treated as academic misconduct and, in our Institution, are subject to 
academic penalties. The rule is strictly applied and is premised on the understanding that both the failure to reference as well as inaccurate referencing practices imply that the thoughts, words and ideas are your own; and if this is not true, then the omission to correctly acknowledge authorship is tantamount to plagiarism, and is treated as academic misconduct.

While ignorance is not an excuse that negates plagiarism, the sanction may, however, vary depending on the identified intention of the wrongdoer. This becomes especially relevant when considering the issue of what is sometimes termed "technical plagiarism" where the student/researcher acknowledges the source but makes errors with the punctuation or the order of information.

Discussing the consequences of "technical plagiarism", Khalid et al. $(2014,3)$ take the more severe approach noting that irrespective of the students' intention or reason, poor referencing is unacceptable and an indication of intellectual laziness, unclear thinking, and inaccurate writing. Similarly, reflecting on plagiarism as a blight on academic integrity, Dunleavy (2014, n.p.) highlights the value of proper referencing and citation pointing out that fundamentally " $[\mathrm{h}]$ ow we cite and reference other work relates back closely and integrally to how we practice science and scholarship". An argument in favour of this approach may be that good referencing practices entrench three fundamental values that are core to higher learning (and hence its integrity) namely, attention to detail, respect, and ethical behaviour.

On the other hand, Santini $(2018,3)$ notes that while poor referencing casts doubt on the individual's academic ability or his/her academic honesty, it is only a suggestion of "potential plagiarism". Studies by Valentine (2006), Elander et al. (2010), and EasyBib (2019), also reflect on the growing body of evidence that finds that plagiarism incidents are most often unintentional, occurring when students fail to apply the proper protocols of referencing because they simply did not know what to do. Valentine $(2006,97)$ argues that when "technical plagiarism" is treated as evidence of dishonesty rather than as "an indication of an authentic beginner engaged in the work of acquiring a new discourse", it generates a strong resistance to the subject that is, in fact, counterintuitive to learning.

\section{THE STUDY}

Our Institution has an exclusive focus on teaching and learning for the fashion industry, including design, production, and retail. The literature to which students are exposed and from which they draw their ideas and references thus extends beyond that of traditional printed sources and includes different forms of media and articles appropriate to the unique curricula of fashion and design. The learning process requires students to showcase new and original ideas and creations, which often involves adaptation and improvement on existing patterns and 
designs. Students utilise a variety of visual, photographic, and tactile sources including ideas from the World's Global Style Network (WGSN), a global trend forecasting platform that presents visual designs, ranges, and fabric prints. Notwithstanding the types of (re)sources, students are required to use the traditional academic referencing standards when delivering their written assignments, projects, and portfolios. Our Institution uses the Harvard method of referencing.

Recognising the need for an effective solution to the mounting problem of technical plagiarism, our Institution implemented a research project to help us identify a solution that combined the standards of authenticity and integrity, and which also dynamically responded to the students' challenges. The objective of the research project was to understand why students continued to make referencing errors even though at the beginning of every year, they received a detailed Referencing Guide, with the Harvard Thumbnail for the design students, supplemented by quarterly workshop sessions, and referencing assessments to develop their familiarity with the activity. The Referencing Guide contains numerous warnings about referencing misconduct and plagiarism penalties are strictly applied. In many cases, the penalties imposed impacted directly on the Institution's throughput and retention rates as students had their assignment marks reduced by as much as thirty per cent because of the penalties applied. As a result, students who would otherwise have passed, failed the assessment. In line with the earlier commentary by Valentine $(2006,97)$ students are often discouraged and, given their greater focus on art and design, many students do not grasp the importance of referencing, perceiving it as "non-essential" to their work. Students consequently find it difficult to understand why they are being punished and then question the Institution's motives and academic approaches.

Recognising integrity and therefore, credibility as a cornerstone of quality teaching and learning, the aim of this research project was twofold: specifically, to proactively support students to understand the purpose of, and reason for, proper academic referencing and citation; and generally, to help them internalise ethical behaviour. In so doing, the Institution hoped to ameliorate its incidence of technical plagiarism and effectively equip students to meet the standards of authenticity and integrity detailed in the NQF and the Institution's Statement on Graduateness. The research project focussed on listening to the student voices to better understand the limitations of the current Institutional practices and gauge the students' opinions on what would enhance learning and improve their understanding for and application of proper academic referencing. Coupled with the students' voices, recommendations and leading practices from other similar studies were researched and considered in the Institutional solution. 


\section{RESEARCH METHOD}

The researchers distributed an online questionnaire using Google Forms to all students. The questionnaire, comprising six questions, was anonymous, and students were requested to reflect on their past experiences with academic referencing and to share improvements that would enhance their understanding and facilitate more responsive engagement with the learning materials provided. The survey was open for two weeks, and one hundred and fifty-two responses $(18 \%$ of the total student population) were received. The sample maintained a confidence level of 95 per cent and a margin error of 6 per cent, thus ensuring both the feasibility and reliability of the findings. Collected data was prepared by Google Forms and then analysed using descriptive statistics.

\section{RESULTS AND ANALYSIS}

Question One required respondents to identify their referencing challenges from a list provided. The menu represented identified plagiarism breaches recorded by the Institutional Integrity Officer during the 2019 academic year. There was also an "Other" option to capture challenges not previously identified. Only 15 respondents (10\%) ticked this box satisfying the researchers that they had efficiently identified the student's areas of concern. All the new issues identified will, however, also form part of the revision process when the Referencing Guide is updated.

Given the Institution's specific discipline focus, it was positive to note that the least challenging referencing activity for students was the referencing of images - only 3 per cent of the respondents (or two students) deemed this activity a challenge. The result established the positive benefit of focussed, repetitive practice in learning the skill of academic referencing. Over the last two years, the Institution had placed particular emphasis on image referencing both in the Referencing Guide and in the additional workshops and practice sessions and implementing strict penalties for defaulting on the prescribed referencing guidelines. The outcomes of the research studies of both Fazilatfar, Elhambakhsh and Allami (2018) and Smedley, Crawford and Cloete (2014) emphasise the importance of practice and feedback. Smedley et al. $(2014,16)$ also confirmed that after a series of interventions and opportunities to practice the referencing skills, "... in the semester following the educational intervention, there was an improvement in assignment referencing". They note, albeit based on anecdotal feedback, that such improvement was sustained in the following semesters.

In-text citation and reference list construction were also not a significant challenge for the respondents - 39 per cent and 32 per cent of the respondents, respectively. The biggest challenge experienced by respondents was the engagement with the actual source matter: 65 per cent of the respondents indicated that they did not know when to reference, 65 per cent did 
not understand the principle of referencing paraphrased and synthesised ideas of other authors, 64 per cent noted that they did not know how to cite direct quotes, and 58 per cent could not correctly identify sources of information. It appears that it is the 3 "Ws" that create the greatest confusion for students namely, what to reference, why to reference, and when to reference. This result is not entirely unexpected given the poor language training skills of school leavers today, many of whom would have had very limited if any, exposure to and prior learning in the competencies of academic writing from source, paraphrasing and referencing. When these students enter higher education, the academic expectation is - rather incorrectly, it is submitted - that they will transition seamlessly and grasp the conceptual intricacies of what is often a very technical discourse. Fazilatfar et al. (2018, n.p.) emphasise that in many cases it was not the students' intention to deceive but rather "their developing competencies in text-responsible writing" that was identified by faculty and without further interrogation, the student was penalised for plagiarism. Like Sowden (2005) they urge that training should be the priority, especially when students enter university from inadequate schooling backgrounds. Similarly emphasising the need for training and practice in such instances, Sowden $(2005,232,227-229)$ stresses the importance for institutions to take specific cognisance of the students' knowledge of plagiarism and understanding of what constitutes cheating and why referencing is essential before summarily charging students with academic misconduct.

An important lesson for the researchers was to avoid the trap of believing that students who are guilty of plagiarism and poor referencing are a homogenous group. The fact is that some students simply do not care, while others honestly do not know what to do, and then there are those candidates who fall in between. A one-size-fits-all Referencing Guide, workshops and assessments will not in themselves achieve the desired outcomes and the Institutional goal. Rather, the findings suggest the need for the Institution's training to be re-considered, planned, and re-designed with a much more nuanced approach that takes cognizance of the students' experience.

The responses indicated that most of the students found the approach of the Institution with its programmed and binary set of instructions, particularly alienating. The approach in the Referencing Guide - either do this or suffer that penalty - clouded the learning potential in hostility and resentment. The students' responses were unequivocal that commanding compliance was antithetical to understanding, adoption and learning. This also informs a further adjustment to the training materials and processes.

Question Two asked respondents to identify the source types that they had encountered in past assessments, the aim being to acquire a sense of the various sources utilised, which would then inform the contents of the Referencing Guide for the following year. Most of the students 
used online sources $(94.7 \%)$, followed by books (76.3\%), journal articles $(72.4 \%)$, and class notes $(62.5 \%)$. The heightened use of online resources, however, brings its own challenges because while technology has created greater access, the large volumes of freely accessible information has made it easier than ever for students to plagiarise. Against this backdrop, it becomes even more critical for students to understand the academic and moral importance of citation and referencing, and the purpose for such standards to be in place. As Penders (2018, 1) notes, "Through the inclusion of references we demonstrate the foundation upon which our studies rest as well as how they are different from previous work". Students need to be guided to understand that taking the words, designs or even the ideas of another - albeit with neither tangible form nor shape - and presenting it as their own, is the same as stealing. Rather interestingly, Sowden $(2005,229)$ raises cultural diversity as a possible explanation/justification for plagiarism in some instances, noting that in some cultures mimicking is a sign of admiration and reverence. "[It] reflects the tradition that enlightenment comes through approximation to an established wisdom rather than by means of individual enterprise," he states. Without dismissing the value in the argument, students must nevertheless be made to realise that an appropriate sign of respect is also required, which comes through acknowledgement of the author/source.

Question Three targeted alternative self-study tools that would support the development of referencing skills. The top three preferences for students were practice sheets (49.7\%), online referencing tests (47\%), and workshops (39.7\%). This finding was significant, given that the Institution had only previously utilised workshops and neither of the other two options. Reflecting on acceptable practices that assist students in understanding how not to plagiarise, Hamill $(2009,5)$ proposes focussing on summarising techniques, which include at least one citation. Sowden $(2005,232)$ suggests using oral presentations as a starting exercise in antiplagiarism training, which he suggests teaches students the art of paraphrasing and synthesis while discouraging plagiarism, "but also [serves] as a means to improve language control". Whether approaching anti-plagiarism training from the oral or written tradition of learning, the consensus appears to be that facilitating students' understanding of the effective techniques of summarisation is the first step to be implemented, before moving on to the activities of citation and proper referencing styles.

Question Four required the respondents to rate their ability to access various listed academic sources. Respondents applied a Likert Scale in which 0 represented "no access at all" while 5 represented "excellent accessibility". The very high prevalence of "sometimes" in the responses raised questions about the credibility and depth of the academic research by the students. Regarding online sources, context-specific trend forecasting platforms such as WGSN 
was the source of information most accessed. This outcome is most likely the consequence of access to the WGSN platform being supported by a dedicated additional training session as part of the teaching and learning programme. Following WGSN, students identified online magazines and reputable news sources as their next most utilised resource. Disconcertingly, no respondents indicated accessing the available online library repositories of books, journal articles and academic databases. The researchers concluded that the students lacked either the knowledge of, or the ability to, access these resources. It is a concern that despite all the training interventions, students (and perhaps many graduates) believe that accessing only online websites, magazines and newspaper articles constitutes credible academic research. Hamill $(2009,10)$ suggests that this may be because "students don't understand the language and vocabulary used in academic books and articles". The corollary is that when students do access these sources, they often lift out statements and paragraphs as soon as there is some recognition for the value of the idea presented, without giving any thought to referencing the source (Sowden, 2005, 229).

The low response rate regarding the accessibility of journal articles is also in direct contradiction to the responses provided to Question One, where respondents indicated that they had "frequently" used journal articles for assessment and research purposes. This inconsistency reinforces the uncertainty factor highlighted earlier where respondents acknowledged that they did not correctly understand different available sources. Without more detailed information, the researchers suggest that the "journals" identified in Question One is more than likely a reference to an online website entitled Journal of Trends, which is not an accredited research-based resource. This feedback, albeit ancillary to the current study, confirms the need for lecturers to strengthen graduate competencies by specifically directing students' attention to credible data repositories and academic sources.

Question Five elicited information on the types of visual aids to which students related that would assist them in accessing information about referencing techniques. The overwhelming preference by students was "examples" which enabled them to easily transpose their sources to the format presented in the example. The researchers conclude that students prefer "examples" which may be more easily copied, rather than being required to actively engage with the learning process (a requirement of both gamification and pop quizzes). At this stage of their referencing confidence, students are uncertain about their ability to learn referencing skills through facilitation: instead, they consider it an application that requires practise over time, and that needs to be supported by relevant (static) information texts. The study cited by Hamill $(2009,8-9)$ further reinforces the opinion that when students are being led, they appear to understand and perform better than when left on their own. Once again, this 
reflects on students not understanding the purpose of referencing, not taking the importance of referencing techniques sufficiently seriously, and not taking the care to learn how to reference correctly.

The respondents also advocated for the greater use of diagrams, colour, images, and explanations that imitated emotions and disrupted the more formulaic and technicist approach traditionally linked to explaining referencing practices and styles. This advice is well-received. Interestingly, active engagement components such as gamification and pop quizzes were not favoured by the respondents, with only 45.4 per cent and 21.7 per cent respectively agreeing that they would create value.

Question Six canvassed the students' readiness to assist with testing the revised Referencing Guide - only 37 per cent of the respondents agreed to participate in the improvement activity.

\begin{tabular}{|c|c|c|}
\hline \multicolumn{3}{|c|}{ SUMMARY OF RESPONSES, CHALLENGES, AND INFERENCE FROM THE STUDY } \\
\hline Question & Responses/Challenges & Inferences \\
\hline $\begin{array}{l}\text { 1. Which of the } \\
\text { following } \\
\text { referencing skills } \\
\text { do you find } \\
\text { challenging? }\end{array}$ & $\begin{array}{l}\text { - Least challenging: } \\
\circ \text { Referencing of images and } \\
\text { in-text citation and reference } \\
\text { list construction. } \\
\text { - Most challenging: } \\
\text { Engagement with the actual } \\
\text { source matter. } \\
\circ \text { Approach of the Institution } \\
\text { with its programmed and } \\
\text { binary set of instructions } \\
\text { was particularly alienating. } \\
\text { Commanding compliance } \\
\text { was antithetical to } \\
\text { understanding, adoption and } \\
\text { learning of the required } \\
\text { skillset. }\end{array}$ & $\begin{array}{l}\text { - Plagiarism cannot simply be equated with } \\
\text { dishonesty. } \\
\text { Poor language training skills of school } \\
\text { leavers today affects appreciation and } \\
\text { application of proper referencing. } \\
\text { There is a direct correlation between an } \\
\text { appropriate educational intervention and } \\
\text { the students' enhanced knowledge and } \\
\text { understanding. } \\
\text { It is important to emphasise and for } \\
\text { students to understand the academic and } \\
\text { moral importance of citation. }\end{array}$ \\
\hline $\begin{array}{l}\text { 2. Which of the } \\
\text { following types of } \\
\text { sources have you } \\
\text { had to reference in } \\
\text { the past for your } \\
\text { assessments? }\end{array}$ & $\begin{array}{l}\text { Most of the students used: } \\
\text { - online sources }(94.7 \%) \text {, } \\
\text { - books }(76.3 \%) \\
\text { - journal articles }(72.4 \%) \\
\text { - class notes }(62.5 \%)\end{array}$ & $\begin{array}{l}\text { - Online resources are unequivocally the } \\
\text { most utilised sources of information. } \\
\text { - Increased use of online resources presents } \\
\text { its own challenges because, while } \\
\text { technology has created access, it has also } \\
\text { made it easier than ever for students to } \\
\text { plagiarise with the large volumes of } \\
\text { information that are so easily available and } \\
\text { freely accessible. } \\
\text { - There are divergent schools of thought on } \\
\text { the influence of culture and mimicking as a } \\
\text { form of admiration: however, students must } \\
\text { learn the appropriate signs of respect in the } \\
\text { milieu of the academe, specifically the } \\
\text { importance of acknowledging sources and } \\
\text { authorship. }\end{array}$ \\
\hline $\begin{array}{l}\text { 3. Which of the } \\
\text { following study } \\
\text { aids would you be } \\
\text { willing to engage } \\
\text { with outside of } \\
\text { class hours to } \\
\text { develop your } \\
\text { referencing skills? }\end{array}$ & $\begin{array}{l}\text { Top three preferences: } \\
\text { - } \quad \text { Practice sheets }(49.7 \%) \\
\text { - Online referencing tests }(47 \%) \\
\text { - } \quad \text { Workshops }(39.7 \%)\end{array}$ & $\begin{array}{l}\text { - This was significant as previously only } \\
\text { workshops were utilized. } \\
\text { - In addition, other studies demonstrate the } \\
\text { success derived from first focussing on } \\
\text { summarizing techniques, paraphrasing, } \\
\text { and synthesizing skills before introducing } \\
\text { citation and referencing techniques. }\end{array}$ \\
\hline
\end{tabular}




\begin{tabular}{|c|c|c|}
\hline \multicolumn{3}{|c|}{ SUMMARY OF RESPONSES, CHALLENGES, AND INFERENCE FROM THE STUDY } \\
\hline Question & Responses/Challenges & Inferences \\
\hline $\begin{array}{l}\text { 4. How would you } \\
\text { rate your ability to } \\
\text { access the } \\
\text { following } \\
\text { academic } \\
\text { sources? }\end{array}$ & $\begin{array}{l}\text { Context-specific trend } \\
\text { forecasting platforms (such as } \\
\text { WGSN) was the source of } \\
\text { information most accessed. } \\
\text { - Online magazines and } \\
\text { reputable news sources. } \\
\text { No respondents indicated } \\
\text { accessing the available online } \\
\text { library repositories of books, } \\
\text { journal articles and academic } \\
\text { databases. }\end{array}$ & $\begin{array}{l}\text { - A key concern from the responses was the } \\
\text { very high prevalence of "sometimes", } \\
\text { raising questions about the credibility and } \\
\text { depth of the academic research conducted } \\
\text { by the students. } \\
\text { - Students lacked either the knowledge of or } \\
\text { the ability to access books, journal articles, } \\
\text { and other academic databases. } \\
\text { - Students also do not always understand } \\
\text { academic resources and cannot distinguish } \\
\text { between accredited journal resources and } \\
\text { other articles from popular press and } \\
\text { commercial online sources. This confusion } \\
\text { may, however, be attributable to the } \\
\text { naming convention of the specific online } \\
\text { site (calling itself a "Journal"). }\end{array}$ \\
\hline $\begin{array}{l}\text { 5. Which of the } \\
\text { following types of } \\
\text { visual aids do you } \\
\text { find helpful to } \\
\text { learn new } \\
\text { methods? }\end{array}$ & 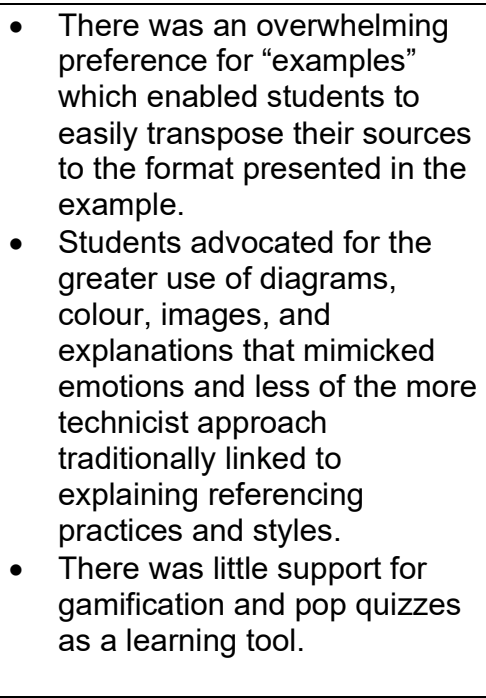 & $\begin{array}{l}\text { This reflects a definite uncertainty by } \\
\text { students regarding referencing skills. } \\
\text { - Students also lack an understanding the } \\
\text { purpose of referencing, do not taking the } \\
\text { importance of referencing techniques } \\
\text { seriously, and are not interested to learn } \\
\text { how to reference correctly, opting rather for } \\
\text { the easier solution of imitation. } \\
\text { Innovative and non-traditional approaches } \\
\text { to explaining referencing styles should be } \\
\text { explored to harness the students' interest in } \\
\text { the skills being taught. } \\
\text { Researchers conclude that students prefer } \\
\text { "examples" as real static information which } \\
\text { may be more easily copied rather than } \\
\text { being required to actively engage with the } \\
\text { learning process which would be a } \\
\text { requirement of both gamification and pop } \\
\text { quizzes. }\end{array}$ \\
\hline $\begin{array}{l}\text { 6. Would you be } \\
\text { willing to help us } \\
\text { by testing and } \\
\text { giving feedback on } \\
\text { the } 2020 \\
\text { referencing guide } \\
\text { in November } \\
2019 ?\end{array}$ & $\begin{array}{l}\text { - Only } 37 \% \text { of the respondents } \\
\text { agreed to participate in the } \\
\text { improvement activity. }\end{array}$ & \\
\hline
\end{tabular}

\section{DISCUSSION AND RECOMMENDATIONS}

The research study provides valuable information on practices to enhance student training in the academic practice of referencing and citation. It was interesting to note that respondents valued examples for specific referencing skills, suggesting that students apply referencing techniques through mimicking existing reference exemplars. Students engaging with a source for which there is no example may experience difficulties and concomitantly commit plagiarism or incur a technical referencing penalty. Alternatively, the student will stop engaging with the source material and find information online, for which there is a referencing example, but the new source may have inferior academic credibility. A key outcome from this is the recognition for the importance of providing students with exemplars of good referencing practices. Whilst 
arguably less intuitive to active learning and inculcating understanding, examples nevertheless continue to present an effective passive learning experience providing students with a useful mirror against which to compare their skills and develop their techniques.

The types of examples provided must include all forms of sources, including new online source formats such as music, video, social media, and business reports that are readily available through online media. This is essential given the increasing utilisation of online materials as a primary source for student information, and one that is identified as a persistent cause of referencing difficulties (Smedley et al. 2014, 13). In this study, the uncertainty of respondents in rating their ability to access other academic sources, further supports the preference for online resources such as internet articles (available by a simple Google search) and a general lack of engagement with materials which typify a more academic form of discourse. Various opportunities exist to address the shortcoming, including re-designing teaching materials to allow for more self-directed learning, where students are guided to the different academic resources and made to locate the information for themselves. However, based on the feedback from Question Three, self-directed learning may not be the anticipated panacea, given the lower level of engagement (49.7\%) that self-study aids had with the respondents. Many factors may contribute to this result including students feeling pressurised by immediate time constraints for their studies, socio-economic challenges, and barriers to learning, either individually or in combination. The idea of self-study outside of the formal curriculum would add to these pressures and, with students being very aware of the high stakes (penalties) involved with incorrect referencing, self-study may be easily confused with isolation. An alternative approach is the more traditional tutorial workshops geared towards familiarising students with the various databases where educational resources may be accessed, and further assisting students in utilising the databases to source information is a valuable academic support system. In this study, the high student rating for the WGSN trend platform for which specific training was provided as part of the formal facilitated learning processes, supports this recommendation.

Additionally, and while confirming the importance of exposing students, especially inexperienced writers, to multiple sources, Yamada (2003) highlights the need for such sources to be pertinently linked to "students' own traditions of study" (Sowden 2005, 226). In this study, in addition to the preferred use of online sources, the respondents also raised the inclusion of colour and graphics as a means of improving the training material and the learning impact. The available literature corroborates this recommendation with neuroscience clarifying the impact of elements that introduce emotion and excitement - such as graphics and colour - on memoryperformance and learning (Dzulkifli and Mustafar 2013; University of British Columbia 2009; 
and Singh 2019).

The research further showed that students experience considerable difficulty gathering, verifying, processing and organising sources of information. Specifically, Questions One and Four provided critical feedback on students' difficulties in identifying source types and their challenges in accessing academic sources. In the context of South Africa, Beute, Van Aswegen and Winberg $(2008,201)$ attribute it quite materially to a problem of inexperience in research, referencing and academic writing skills. Additionally, notes Hamill $(2009,12)$ while the problem is serious enough for native language speakers to grasp, "throw in second language interference and cultural differences and it further complicates the issues". This provides an extra nuance to the type and level of training that must be provided to students in the tertiary environment, and in such cases, penalties will not solve the problem. Keck $(2014,5-6,18)$, however, challenges the conclusions of Hamill (2009) arguing that such stereotyping falls into the trap of "homogenising" incredibly diverse individuals into generic categories without supporting authority. More prosaically, the research findings from the EasyBib survey (2019, np) suggest that problems with citations and poor referencing may rather reflect the reality that formatting may simply be too confusing for some students. The different schools of thought provide an interesting avenue for further research, especially as institutions formulate their referencing tools and training to promote fitness for purpose.

One of the most concerning outcomes of this study was the assertion that faculty themselves did not always adhere to the Institutional referencing conventions and approved policies. In a student culture fixated with examples, this can manifest in a weak pedagogical alignment and contribute to students' confusion in what is often a foreign and technical subject. Pecorari (2006, 9), describes this problem of mixed-messaging as one of the biggest complications when seeking to embed a good referencing culture noting the need for feedback but explicitly highlighting the point that:

"the inconsistency and failure to provide sufficient (or consistent) feedback on [incorrect citations] and inappropriate source use from instructors may lead to a wrong assumption by students that their referencing is correct".

Where faculty apply inconsistent norms, it creates confusion and may exacerbate student frustration. In this study, the researchers noted an obvious difference in the standards applied by the full-time faculty and those applied by the industry experts, who were less convinced of the value of correct referencing and citation practices. In disciplines where industry practitioners are vital, it becomes increasingly important to ensure that uniform standards are maintained through staff training and professional development.

Therefore, arising from the research project the following summary of findings and 
recommendations is made:

\begin{tabular}{|ll|}
\hline \multicolumn{1}{|c|}{ SUMMARY OF THE FINDINGS AND RECOMMENDATIONS } \\
\hline (i) $\begin{array}{l}\text { Examples should be used in all training guides and programmes to practically demonstrate how referencing and } \\
\text { citation techniques must be applied. }\end{array}$ \\
\hline (ii) $\begin{array}{l}\text { While all possible sources of information should be including in the exemplars, newer online sources such as } \\
\text { music, pictures, videos, social media, and blogs are increasingly identified as key sources of information for the } \\
\text { students. }\end{array}$ \\
\hline (iii) $\begin{array}{l}\text { Repeated exercises and feedback are necessary. However, additional self-directed learning is not always the } \\
\text { best approach in training students in the art of referencing. It may be more important for training in the skills of } \\
\text { good referencing to be integrated into the teaching and learning programme or engaged through facilitated } \\
\text { workshops. }\end{array}$ \\
\hline (iv) $\begin{array}{l}\text { Anything the introduces positive emotion into the learning experience will inspire memory and concurrently } \\
\text { learning. This is especially relevant when training students in referencing techniques which is often not their } \\
\text { primary interest. }\end{array}$ \\
\hline (v) $\begin{array}{l}\text { There is no consensus on whether students' lack of research experience, or cultural differences (and especially } \\
\text { being second-language English speakers) further problematises their ability to apply referencing skills and } \\
\text { techniques. Further research in this area is required especially as institutions focus on training that is fit for } \\
\text { purpose. However, one facet is clear - penalties are not always the solution to promote students' understanding } \\
\text { of referencing and citation techniques. }\end{array}$ \\
\hline (vi) $\begin{array}{l}\text { There is no gainsaying that academic referencing practices and scholarship can be extremely confusing with } \\
\text { the many styles differing by content order, punctuation, use of italics and underlining etc. Institutions must be } \\
\text { explicit and consistent in their chosen style and practice. In this regard. staff training is critical to ensure } \\
\text { uniformity of applied standards across the institution. This may be especially applicable where faculty includes } \\
\text { industry specialists and experts for whom academic traditions of citation may be less significant. }\end{array}$
\end{tabular}

\section{CONCLUSION}

Academic integrity is a shared standard of quality and graduateness and includes the intrinsic values of ethical decision-making, honesty, fairness, responsibility, respect, and trustworthiness. Understanding and avoiding plagiarism and applying right referencing skills is one way that higher education instils the qualities of integrity, honesty, and respect. It is essential to realise that understanding the purpose of proper citation and how to apply referencing norms is not exclusive to the higher education sector - it has a far more comprehensive application, especially in today's information-rich society.

However, applying the lens of quality higher education, continuous review and critical stakeholder engagement is a cornerstone of improvement. In this project, one of the most valuable lessons was the role of the students in the self-reflection and learning process for improvement. Engaging with students' voices provided a powerful reminder that how it has always been done is not necessarily effective or the best way of sharing information and knowledge. As soon as this dialogue platform opened between the students and the faculty, the potential to improve teaching and learning practices in support of the new generation student was meaningfully strengthened and new ways of doing came to the fore.

\section{REFERENCES}

Bialystok, Lauren. 2017. Authenticity in education. Oxford Research Encyclopaedia of Education. https://doi.org/10.1093/acrefore/9780190264093.013.168.

Beute, Nico, Elizabeth S. van Aswegen and Christine Windberg. 2008. Avoiding plagiarism in contexts of development and change. IEEE Transaction on Education 51(2) (June): 201-205. https://doi.org/10.1109/TE.2007.912407. 
Dunleavy, Patrick. 2014. Poor citation practices are continuing to harm the humanities and social sciences. LSE (blog), December 9, 2014. www.blogs.lse.ac.uk/impactofsocialsciences/ 2014/12/09/poor-citation-practices-humanities-and-social-sciences/

Dzulkifli, Mariam A. and Muhammad F. Mustafar. 2013. The influence of colour on memory performance: A review. Malaysia Journal of Medical Science 20(2) (March): 3-9. www.ncbi.nih.gov/pubmed/23983571

EasyBib. 2019. 10 Facts about students and plagiarism. January 14, 2019. https://www.easybib.com/ guides/10-facts-about-students-and-plagiarism/

Elander, James, Gail Pittam, Joanne Lusher, Pauline Fox and Nicola Payne. 2010. Evaluation of an intervention to help students avoid unintentional plagiarism by improving their authorial identity. Assessment and Evaluation in Higher Education 23(2): 157-171. https://oi.org/10.1080/ 02602930802687745.

Fazilatfar, Ali M., Seyyedeh E. Elhambakhsh and Hamid Allami. 2018. An investigation of the effects of citation instruction to avoid plagiarism in EFL academic writing assignments. SAGE Open 8(2) (April). https://doi.org/10.1177/2158244018769958.

Hamill, Sarah J. 2009. Challenging ESL students to avoid plagiarism and properly summarize and cite articles. Works of the FIU Libraries 19. https://digitalcommons.fiu.edu/glworks/19

Keck, Casey. 2014. Copying, paraphrasing and academic writing development: A re-examination of L1 and L2 summarization. Journal of Second Language Writing 25: 4-22. http://dx.doi.org/ 10.1016/j.jslw.2014.05.005.

Khalid, Adeel, Beth Stutzmann, Margaret L. Lowder, Mir M. Atiqullah, Rajnish Singh and Craig A. Chin. 2014. Academic misconduct at a Polytechnic University - Case studies. Paper presented at the $21^{\text {st }}$ ASEE Annual Conference and Exposition, Indianapolis. June 15-18, 2014. https://researchgate.net/publication/287275531_Academic_misconduct_at_a_polytechnic_univer sity_-_Case_studies

Pecorari, Diane. 2006. Visible and occluded citation features in postgraduate Second-Language writing. English for Specific Purposes 25(1) (December): 4-29. https://doi.org/10.1016/ j.esp.2005.04.004.

Penders, Bart. 2018. Editorial ten simple rules for responsible referencing. PLoS Computational Biology 14(4) (April): e1006036. https://doi.org/10.1371/journal.pcbi.1006036.

Santini, Ario. 2018. The importance of referencing. The Journal of Critical Care Medicine 4(1) (October): 3-4. https://doi.org/10.2478/jccm-2018-0002.

Singh, Divya. 2019. Using neuroscience and psychophysiological feedback to improve online material. Paper presented at the Contact North / Contact Nord Online Learning 2019 Global Summit and EdTech Expo, Ontario. October 8-10, 2019. https://globalonlinelearningsummit.ca/\#

Smedley, Alison A., Tonia Crawford and Linda Cloete. 2014. An intervention aimed at reducing plagiarism in undergraduate nursing students. Nurse Education in Practice 15(3) (December): 168-173. https://doi:10.1016/j.nepr.2014.12.003.

Sowden, Colin. 2005. Plagiarism and the culture of multilingual students in higher education abroad. ELT Journal 59(3) (July): 226-233. https://doi.org/10.1093/elt/cci042.

University of British Columbia. 2009. Effect of colours: Blue boosts creativity, while red enhances attention to detail. ScienceDaily February 6, 2014. www.sciencedaily.com/releases/2009/ 02/090205142143.htm

Valentine, Kathryn. 2006. Plagiarism as literacy practice: Recognising and rethinking ethical binaries. College Composition and Communication 58(1) (September): 89-109. https://www.jstor.org/ stable/20456924.

Yamada, Kyoko. 2003. What prevents ESL/EFL writers from avoiding plagiarism? Analyses of 10 North American websites. System 31(2) (June): 247-258. https://doi.org/10.1016/S0346251X(03)00023-X. 